\title{
Una aproximación a la creación jurisprudencial del Derecho en Cuba a partir de los tres modelos de juez de F. Ost
}

\author{
Carlos Bruzón Viltres* \\ Lianet Palacio Castillo**
}

\begin{abstract}
RESUMEN
En el presente artículo se analizan algunos aspectos de la creación jurisprudencial del Derecho en el contexto jurídico cubano, a partir de la relevancia de la función judicial en los tiempos actuales y de las dificultades identificadas debido a la indeterminación de las fuentes formales del ordenamiento jurídico. Se destaca el papel de los órganos judiciales superiores en Cuba en la solución de los más diversos y complejos problemas de la sociedad, relacionándolo con los modelos de juez descritos por François Ost.
\end{abstract}

Función judicial en Cuba - jurisprudencia - modelos de juez

\section{An approach to the judicial creation of law in Cuba from the three models of judge according F. Ost}

\begin{abstract}
In this paper we analyze some aspects of the judicial creation of law in the Cuban legal context, the importance of the judiciary in the present times and the difficulties identified due to the indeterminacy of the formal sources of law. We emphasize in the role of the higher judiciary in Cuba in solving the most diverse and complex problems of society, relating it to models of judge according François Ost.
\end{abstract}

Cuban judiciary - jurisprudence - models of judge

* Máster en Derecho Internacional Público por la Universidad de La Habana, Cuba. Profesor de Teoría General del Derecho. Correo electrónico: cbruzonv@udg.co.cu

** Profesora de la disciplina de Fundamentos teóricos y constitucionales del Estado y del Derecho, Departamento de Derecho, Universidad de Granma, Cuba. Correo electrónico: lpalacioc@udg.co.cu

Artículo recibido el 1 de junio de 2013 y aceptado para su publicación por el Comité Editorial el 29 de octubre de 2014 . 


\section{Punto de Partida: los tres modelos de Juez SEgún François Ost}

$\mathrm{E}$ n el número 14 de los cuadernos de filosofía jurídica Doxa, el reconocido profesor belga François Ost plantea una interesante caracterización de los tres modelos de juez ${ }^{1}$. El estudio refleja una evolución del papel de la función judicial, que arranca desde la concepción de un juez inscrito en el modelo de Derecho “jupiterino", trascendental, sagrado y legalista, transcurre por la idea del "juez Hércules” de inspiración dworkineana -propio del realismo jurídico norteamericano y en particular de la sociological jurisprudence-, y culmina con la noción del "juez Hermes", una especie de "juez red" reflejo de los intereses y complejidades de una sociedad en transformación.

No es el propósito estricto del presente artículo ofrecer una interpretación individual de la propuesta de Ost. Mucho menos realizar una crítica a sus fundamentos. Se trata, esencialmente, de identificar algunos presupuestos teóricos ínsitos en su argumentación, que encajan perfectamente con una realidad muy actual. Estos -aunque la afirmación parezca incluso lejana a contextos como el cubano, política y jurídicamente hablando-, poseen una materialidad y adaptación comprobables.

Por esta misma razón, tampoco nos detendremos en los extremos de la teoría lúdica del Derecho esbozada por el autor, sino solamente en el papel que desempeña la función judicial en los tiempos que corren. Papel que no ha de limitarse - por la denominación dada al último modelo de juez expuesto: Hermes- a las cuestiones de interpretación normativa, sino que ocupa un interesante lugar entre la inclinación convencionalista del “juez Júpiter” y la innovadora del "juez Hércules”. Resultado de esto, como el propio Ost destaca, la posición del "juez Hermes”, "respeta el carácter hermenéutico o 'reflectante' del juicio jurídico que no se reduce ni a la improvisación ni a la simple determinación de una regla superior" 2 .

En conexión con esta afirmación resulta válido subrayar el rol atribuido a la administración y, particularmente, a la administración de justicia, en el proceso de producción normativa. Es el caso, comentado por el profesor belga, en que "la función jurisdiccional se difunde en el conjunto de los otros poderes [que nosotros denominamos funciones] (...)"3, mediante las más diversas manifestaciones, suscribiendo la conclusión de Morand respecto de que "por razón de los problemas que debe resolver el Estado asistencial y de la acción en red que desarrolla, la administración es el centro de la producción y de la puesta en práctica de las normas" 4 .

Aun pasadas más de dos décadas de estas aseveraciones y distinguiendo los posibles puntos que bien no pudieran coincidir contextualmente con la concepción de Estado

\footnotetext{
${ }^{1}$ Cfr., Ost, F., "Júpiter, Hércules, Hermes: tres modelos de juez", en Doxa. Cuadernos de Filosofía del Derecho, Universidad de Alicante, núm. 14, 1993, pp. 169-194.

${ }^{2}$ Ídem, p. 189.

3 Ídem, p. 184.

${ }^{4}$ Ibidem, nota 26.
} 
asistencial ${ }^{5}$ descrita, a la administración de justicia se le pone en el centro de las más diversas problemáticas jurídicas, cuya solución no depende ya de un legislador pleno, omnipotente y suficiente (como se ha intentado definir siempre al legislativo de base romano-francesa), y sí de una dosis importante de intervención y creación desde el judicial. Incluso, este hecho no se reduce a estos Estados asistenciales -término que viene sufriendo una especie de decadencia conceptual-, sino a cualquier organización política, por la creciente dinámica de las relaciones jurídicas y la complejización de la vida social.

De esta forma, intentaremos describir los importantes cambios que se van produciendo en nuestro sistema jurídico, desde la óptica de la emergencia de una forma de creación jurídica (de fuente del Derecho) muy peculiar, asentada en la labor de los tribunales, específicamente de los órganos judiciales superiores. Se trata de una manifestación jurisprudencial que pone de relieve la constante preocupación del juez por resolver las problemáticas que se presentan en la sociedad dinámica y compleja, y también la superación del paradigma de juez-solo-intérprete, de ese "juez jupiterino" característico del modelo continental decimonónico.

\section{EL PROBLEMA DE LA INDETERMINACIÓN DEL SISTEMA DE FUENTES EN CUBA Y LA POSICIÓN DE LA JURISPRUDENCIA}

Para el caso singular de Cuba el problema de origen debe situarse en la indeterminación normativa de las fuentes del Derecho. Algunos autores ${ }^{6}$ han insistido en las posibles causas de la omisión del sistema de fuentes de nuestro ordenamiento, de lo que solo destacaremos el comprobado distanciamiento entre este horizonte formal y lo que acontece en la práctica.

Este problema erróneamente pudiera considerarse como una simple cuestión teórica. O ser, en última instancia, reducido al campo del formalismo jurídico. Sin embargo, son innumerables los autores que han advertido acerca de la importancia de la delimitación de las fuentes jurídicas de un ordenamiento dado, al tiempo que la práctica concede razón a la trascendencia, incluso política, de este hecho ${ }^{7}$.

5 En el entendido conceptual de caracterizar a nuestro Estado estrictamente en los términos de Estado asistencial, sin que a ello le reste la misión comprobada de Estado "pedagogo", "redistribuidor" o "compensador" (empleando los mismos términos de Ost), ocupado de los múltiples y complejos problemas de la sociedad -que también sustentan la imagen del "juez red” que comentamos en el presente artículo-.

${ }^{6}$ Cfr., inter alia, Pérez Carrillo, J.R., "Causas de indeterminación en el sistema de fuentes del Derecho", en Problema. Anuario de Filosofía y Teoría del Derecho, núm. 4, 2010, pp. 303-322. Hemos planteado algunas consideraciones al respecto en: Bruzón Viltres, C.J., "Fuentes del Derecho en Cuba: indeterminación, efectos, posibles soluciones”, en Revista General de Derecho Público Comparado, núm. 14, 2014, pp. 1-31.

${ }^{7}$ Nos identificamos frecuentemente en este punto con una expresión de Díez Picazo, cuando sentenciaba que el problema de las fuentes, su enumeración y establecimiento de su jerarquía, "es ante todo, un problema político, porque entraña el especial reconocimiento de un ámbito de poder -poder mandar y poder hacer obedecer- que en última instancia es un poder de naturaleza política” ( $C f r$., Díez Picazo, L.; Gullón, A., Sistema de Derecho Civil, 8va. ed., Tecnos, Madrid, 1994, p. 98). 
Las tensiones que se manifiestan en el contexto doctrinal y normativo cubano superan la posible orientación reduccionista de la idea de fuente del Derecho. Lo decimos en el sentido de que en ocasiones se restringe el empleo del término a los modos de creación normativa, al origen del fenómeno jurídico en sí, abandonando la idea de fundamento de validez o de existencia, como lo exponen, i. e., Kelsen ${ }^{8}$ o Raz ${ }^{9}$, y otra multiplicidad de significados que comprende esta expresión.

En Cuba la problemática se concentra en la admisión de una u otras fuentes con los efectos antes descritos. Doctrina dominante durante décadas ha sido la de entender como único modo de creación jurídica y por ende, como norma válida, al acto normativo, a la ley en sentido genérico. Como puede comprobarse de la lectura de los textos más ampliamente difundidos en nuestro país para la enseñanza del Derecho ${ }^{10}$ (especialmente desde los años ochenta del pasado siglo) esta postura no solo ha recibido el influjo del legalismo típico del sistema continental, sino también de la construcción dogmática de la escuela socialista del Derecho, particularmente de autores del extinto campo socialista de Europa del este.

Este signo ha distinguido al mismo tiempo el pensamiento jurídico cubano, que desde la perspectiva iusfilosófica ha transitado con mucha dificultad -empleando las definiciones de los propios autores de referencia- desde un voluntarismo ontológico al positivismo ideológico ${ }^{11}$, reflejo de la pobreza y ortodoxia de algunas de las interpretaciones realizadas a la teoría marxista del Derecho.

En fin, nos encontramos ante una escena contradictoria entre lo que nos atrevemos a denominar como posturas excluyente e incluyente o plural. Para la primera es el acto normativo y solo este, norma válida, Derecho en sí mismo. Para la segunda, no es posible pensar un ordenamiento jurídico con existencia limitada a esta fuente sino que, por el contrario, se distinguen, bien en la práctica, bien en la indagación científica (sustentada obviamente en la práctica), otras manifestaciones de creación jurídica que sobrepasan la existencia única de la ley.

En otras oportunidades se han planteado resultados parciales de instrumentos aplicados que reflejan la inclinación dominante hoy, sobre todo entre los operadores jurídicos (la práctica jurídica), en cuanto a la identificación de las fuentes formales del ordenamiento jurídico cubano ${ }^{12}$. De tal suerte, además del acto normativo -insoslayable fuente formal por excelencia de nuestro sistema jurídico-, también se plantea la existencia

${ }^{8}$ Kelsen, H., Teoría pura del Derecho (trad. de R. Vernengo), UNAM, México, 1982, p. 243.

${ }^{9}$ Raz, J., The Authority of Law, Oxford, Oxford University Press, 1979, p. 67.

${ }^{10}$ Entre otros: Fernández Bulté, J., Teoría del Estado y el Derecho, 2 tomos, Editorial Félix Varela, La Habana, 2004; Cañizares Abeledo, F.D., Teoría del Derecho, Editorial Pueblo y Educación, La Habana, 1979; Jawitsch, L.S., Teoría General del Derecho, Editorial de Ciencias Sociales, La Habana, 1988; Zhidkov, O.; Chirkin, V.; Yudin, Y., Fundamentos de la Teoría Socialista del Estado y el Derecho, Editorial Progreso, Moscú, 1980.

${ }^{11}$ Carrillo García, Y; Mondelo, W., "Del voluntarismo ontológico al positivismo ideológico (una lectura del pensamiento jurídico cubano)", en Revista Crítica Jurídica, núm. 29, ene.-jun. 2010, pp. 181-217.

${ }^{12}$ Cfr., v. gr., Bruzón Viltres, C.J., "Jurisprudencia en Cuba: análisis de las consecuencias de su reconocimiento como fuente formal del ordenamiento jurídico”, en Opinión Jurídica, Medellín, vol. 12, núm. 23, 2013, pp. 185-186 y Ferrari Yaunner, M., Los principios de legalidad y seguridad jurídica como fundamentos 
y aplicabilidad de los principios generales del Derecho, de la jurisprudencia y de la analogía. En menor medida se reconocen a los tratados internacionales y la costumbre.

Este dato, de por sí, reconfigura el mapa del reconocimiento de las fuentes formales del ordenamiento cubano, al tiempo que ayuda a reconstruir la noción sistémica de nuestro Derecho, al menos desde esta arista ${ }^{13}$. Por supuesto, instrumentos limitados en su alcance no serían suficientes para sostener tal afirmación, por lo que resulta necesario recurrir a lo que pudieran denominarse como otros patrones de identificación de las mencionadas fuentes formales.

Pues bien, este es el punto de partida para explicar la importancia que va ganando en nuestro escenario jurídico la creación jurisprudencial del Derecho, a partir de la actividad de los órganos judiciales superiores, en especial, el Consejo de Gobierno del Tribunal Supremo Popular.

Antes de adentrarnos en el centro de este análisis, debemos insistir en que, junto a la indeterminación normativa del sistema de fuentes, se produce la indefinición de los principios de organización de dichas fuentes, hecho que acarrea serias dificultades desde el punto de vista de la competencia y la jerarquía normativa ${ }^{14}$. Así, en medio de un complejo proceso de transformaciones sociales, económicas y políticas en el que se encuentra inmerso nuestro país, las limitaciones en torno a la determinación y aplicabilidad de estos criterios coloca en una posición riesgosa a los principios técnicos del ordenamiento jurídico (fundamentalmente el de constitucionalidad y el de jerarquía normativa), allana el camino a problemas funcionales como las antinomias y las lagunas normativas y genera una contradicción de base social relacionada con las afectaciones del principio de seguridad jurídica.

Precisamente a estas dificultades debe enfrentarse el "juez Hermes” de estos tiempos, que intentamos extrapolar a nuestra realidad en este estudio.

\section{En torno a la JURISPRUdenCia COMO FUENTE FORMAL DEL DeRECho. ESPECIAL REFERENCIA AL CONTEXTO JURÍDICO CUBANO}

Abundante doctrina existe en relación con el tema de la jurisprudencia como fuente del Derecho. Esta se ha hecho acompañar de una rica polémica, inicialmente ubicada

del proceso de integración del Derecho para colmar las lagunas de la ley en Cuba, tesis presentada en opción del grado científico de Doctor en Ciencias Jurídicas, Universidad de La Habana, 2010, anexo 5.

${ }^{13}$ Algunos elementos sobre el necesario proceso de reconstrucción sistémica de nuestro ordenamiento jurídico, a partir de sus fuentes formales y con la especial participación de la función judicial, en: Bruzón Viltres, C.J., "El papel activo del juez en el proceso de reconstrucción sistémica del Derecho en Cuba, a partir de la integración de sus fuentes formales", en elDial.com. Suplemento de Derecho Procesal, 25 de marzo de 2014. Disponible en: http://www.eldial.com/nuevo/lite-tcd-detalle.asp? $\mathrm{id}=7327 \&$ base $=50 \&$ id_publicar $=\&$ fecha_pu blicar $=25 / 03 / 2014 \&$ indice $=$ doctrina\&suple $=$ Procesal. Acceso en: 26 de marzo de 2014 .

${ }^{14}$ Estos precisamente son, en palabras de Crisafulli, dos de los más importantes criterios de ordenación de las fuentes. Cfr., Crisafulli, V., "Jerarquía y competencia en el sistema constitucional de las fuentes", en Revista de Derecho Constitucional Europeo, núm.1, 2004, pp. 323-353. 
en la determinación del carácter o no de fuente de la actividad de los órganos judiciales según el sistema de Derecho de referencia. Aunque, como han advertido algunos autores, la distinción entre los sistemas romano-francés y anglosajón, a partir del mayor o menor grado en que se reconoce a la jurisprudencia como fuente, ha perdido virtualidad y valor descriptivo, debido entre otras razones a la progresiva codificación del common law y a la influencia cada vez más creciente en el Derecho continental de la jurisdicción constitucional ${ }^{15}$.

Por otro lado, el término jurisprudencia posee una polisemia que ha generado dificultades en torno a su identificación y explicación, extremo en el que no pretendemos detenernos. Es por ello que, a los efectos del presente estudio, entendemos esta institución en el sentido de creación judicial del Derecho, de fuente formal ${ }^{16}$.

Para Cuba la evolución de la jurisprudencia desde esta óptica ha atravesado por distintas etapas. Respecto del período de dominación colonial de la isla (1492-1898), tal evolución marchó casi al unísono de las transformaciones del Derecho español, en donde pueden descubrirse interesantes datos en la doctrina histórica. Lo cierto es, como apunta López Medina, que el Derecho continental (especialmente el francés) resultó tener bastante de judicial y que, en distintos momentos, se mostraron inclinaciones importantes a la aceptación del papel de la jurisprudencia en España (sobre todo bajo el influjo de la doctrina legal en pleno siglo XIX) ${ }^{17}$. Con la entrada en vigor en Cuba del Código Civil español, por Real Decreto de 31 de julio de 1889, también se adoptan las tendencias del momento y se asimilaba el valor relativo que se daba en aquel texto a la jurisprudencia.

La denominada etapa neocolonial en Cuba (1901-1958) ofrece un panorama distinto. Personalidades jurídicas de entonces defendieron vehementemente el carácter de fuente de la jurisprudencia, llegándose a comparar su valor normativo al de la ley. Una

${ }^{15}$ V. gr., Lafuente Balle, J.M., La judicialización de la interpretación constitucional, Editorial Colex, Madrid, 2000; David, R.; Jauffret-Spinosi, C., Los grandes sistemas jurídicos contemporáneos (trad. de J. Sánchez Cordero), UNAM-Centro Mexicano de Derecho Uniforme-Facultad Libre de Derecho de Monterrey, México, 2010; Taruffo, M., "Precedente y jurisprudencia”, en Precedente. Anuario Jurídico, 2007, pp. 85-99; Hierro, L., "El imperio de la ley y la crisis de la ley”, en Doxa. Cuadernos de Filosofía del Derecho, núm. 19, 1996, pp. 287-308.

16 Siguiendo a García Maynez, en el sentido más "llano" del término "por fuente formal entendemos los procesos de creación de las normas jurídicas”. Vid., García Maynez, E., Introducción al estudio del Derecho, 32da. ed., Editorial Porrúa, México, 1980, p. 51.

${ }^{17}$ Así nos muestra este autor el interés por compendiar la jurisprudencia de la época, en los casos del Recueil de sentencias de Armand Dalloz en Francia, que vio la luz en el 1827, posteriormente ampliado en 1845 (Répertoire methodique et alphabétique de législation, de doctrine et de jurisprudence en matière de droit civil, commercial, criminel, administratif, de droit des gens et de droit public) y del Repertorio de jurisprudencia civil española, ó Compilación completa, metódica y ordenada por órden alfabético de las diversas reglas de jusrisprduencia sentadas por el Tribunal Supremo de Justicia, publicado entre 1867 y 1884 por José María Pantoja, obras que también tuvieron "émulos" en América Latina, como señala López Medina. Considerando la importancia de la jurisprudencia constante en Francia, autores como Geny y Duguit llegaron a afirmar que a finales del siglo XIX "gran parte del nuevo derecho francés era verdaderamente judicial”. Cfr., López Medina, D., "Tres caminos históricos en la formación de la jurisprudencia en América Latina: Recepción y vicisitudes del concepto de "doctrina legal' en la región”, en González, A. y Del Río, J., (comps.), Discusión jurídica contemporánea desde Michoacán, Tribunal Electoral del Estado de Michoacán, México, 2011, pp. 9-10. 
de las opiniones más contundentes corresponde a quien fuera Presidente del Tribunal Supremo, José A. del Cueto, que en solemne sesión de apertura del año judicial de 1918-1919 dejaba establecido:

“(...) la jurisprudencia vive no solo debajo de la Ley, como vasalla, para aclarar su obscuridad y suplir su deficiencia, sino a su lado, como igual, para sustituirla cuando silencia el caso a decidir, y hasta por encima de la propia Ley para fijar la inteligencia que en la práctica ha de dársele y corregir como errónea cualquier interpretación que discrepe de la que la misma jurisprudencia estableció" ${ }^{18}$.

Casi dos décadas después, uno de los más prominentes juristas cubanos, Antonio S. de Bustamante y Montoro, interpretando el artículo 1.689 del citado Código Civil español vigente en Cuba, afirmaba:

"La doctrina legal, como claramente se infiere de las sentencias dictadas, coincide con el concepto de la jurisprudencia de manera que la norma que de ella emana está situada en el mismo rango de fuente jurídica que la ley, aunque precedida de una conjunción disyuntiva, que le da carácter supletorio (...) La norma jurisprudencial, por consiguiente, tiene, del mismo modo que la ley, una esfera de aplicación extrajudicial, dentro de la vida social misma, como cualquiera otra norma positiva" ${ }^{19}$.

Hemos seleccionado estos dos fragmentos no solo por el valor doctrinal e histórico que poseen, sino para confirmar la inteligencia de la época en torno al carácter de fuente formal atribuido a la jurisprudencia. Bien equiparada, por encima o con carácter supletorio respecto de la ley, pero con un inobjetable valor normativo.

Esta idea alcanzó su realización más amplia con la instauración del Tribunal de Garantías Constitucionales y Sociales, una Sala especial perteneciente al Tribunal Supremo instaurado con la Constitución de 1940. La incidencia de aquella peculiar jurisdicción constitucional da continuidad a lo que el profesor García Belaúnde denomina como "modelo de control cubano", basado en el "recurso de inconstitucionalidad" de carácter general reglamentado en la ley especial de 1903, que fragua posteriormente en la acción pública de inconstitucionalidad con la Ley Constitucional del 1934.

Las sentencias emanadas de esta instancia generaron una interesante jurisprudencia (incluso en su sentido de creación normativa), aunque, para hacer justicia desde el punto de vista histórico, tal Sala fue perdiendo credibilidad tras no oponerse al golpe de Estado del dictador Fulgencio Batista, que culminó desconociendo la Constitución de 1940, colocando en su lugar unos estatutos constitucionales totalmente ilegítimos.

${ }^{18}$ Del Cueto, J.A., Discurso leído en la solemne apertura de los tribunales el 2 de septiembre de 1918, Librería e Imprenta "La Moderna Poesía", La Habana, 1918, p. 4.

19 De Bustamante y Montoro, A.S., La jurisprudencia en la jerarquía de las fuentes del Derecho positivo cubano, 2da. ed., Jesús Montero Editor, La Habana, 1937, pp. 17-18. 
Desde 1959 hasta la fecha se han sucedido importantes variaciones que han ido desde reconocer el papel activo de la judicatura en la formación del nuevo Derecho revolucionario, hasta la supresión de toda mención a las fuentes formales del Derecho, incluyendo la jurisprudencia, de la norma civil sustantiva ${ }^{20}$. Esto indica que, en exacta medida, la cuestión del reconocimiento de la jurisprudencia como fuente en el ordenamiento jurídico cubano ha sufrido los mismos vaivenes teóricos y normativos que la discusión en cuanto al sistema de fuentes del Derecho en general.

Como expresamos líneas arriba, una tendencia más flexible comienza a plantearse en las últimas décadas. De las posiciones estudiadas ${ }^{21}$ y de la opinión de operadores jurídicos, tres son las manifestaciones más importantes vinculadas a la noción de jurisprudencia en el contexto jurídico cubano actual:

- Fundamentación (ratio decidendi) de las sentencias.

- Reiteración de fallos en la resolución de asuntos de similar naturaleza, fundamentalmente provenientes de las salas del Tribunal Supremo Popular.

- Instrucciones con carácter obligatorio emanadas del Consejo de Gobierno del Tribunal Supremo Popular, dictadas para lograr la uniformidad en la práctica y la interpretación de las leyes por todo el sistema de tribunales.

Interesante se vuelve también la identificación de la jurisprudencia en el análisis de la causal de casación contenida en el artículo 630.1 de la Ley de Procedimiento Civil, Administrativo, Laboral y Económico ${ }^{22}$ y del principio de non liquet, al tenor del artículo 3 de la misma disposición normativa ${ }^{23}$, así como del artículo 7 e) de la Ley de los Tribunales Populares ${ }^{24}$.

${ }^{20}$ Un recuento acerca de esta evolución puede revisarse en: Matilla Correa, A., "Comentarios sobre las fuentes del Derecho Administrativo cubano (excepto el reglamento)", en Castanedo, A. et al., Temas de Derecho Administrativo cubano, Editorial Félix Varela, La Habana, 2006, pp. 33-219 y en una línea similar: Bruzón Viltres, C.J., Tamayo Blanco, I., "La jurisprudencia en Cuba: reconocimiento dentro del sistema de fuentes del Derecho y posibles consecuencias", en Boletín Mexicano de Derecho Comparado. Nueva serie, vol. XLVII, núm. 139, 2014, pp. 290-298.

${ }^{21}$ Algunos criterios analizados en la doctrina interna: Simón, L., "Un acercamiento a la jurisprudencia como fuente formal de Derecho: su origen romano y su recepción en Cuba", en Revista General de Derecho Romano, núm. 10, 2008, pp. 1-12; Mendoza Díaz, J. et al., Lecciones de Derecho Procesal Civil, Editorial Félix Varela, La Habana, 2001, p. 18; Rodríguez Sánchez, C.F.; Hernández, R., "La jurisprudencia como fuente complementaria del Derecho", en Memorias de la IV Conferencia Científica sobre el Derecho, Santiago de Cuba, Universidad de Oriente, 1997, p. 41.

${ }^{22}$ Sobre este análisis, la obra de referencia del profesor Mendoza Díaz.

23 "La jurisdicción de los Tribunales cubanos es indeclinable. Los Tribunales no pueden rehusar el conocimiento de los asuntos si cualquiera de los litigantes es cubano o se refieren a bienes situados en Cuba, aunque sobre lo mismo exista pleito pendiente en otro país o haya habido sumisión a Tribunales extranjeros, aun arbitrales".

24 "(...) obligación de los tribunales de dictar los fallos o sentencias definitivas y demás resoluciones judiciales que procedan, sin que sea admisible excepción o excusa alguna”. 
Retomando los modelos de juez propuestos por François Ost, podemos resumir que las posiciones en torno a la identificación del carácter de fuente de la jurisprudencia que, en buena medida, sirven de base al reconocimiento del papel preponderante de la función judicial en distintos momentos históricos, reflejan una tendencia hacia la configuración de un "juez Júpiter” de corte continental, legalista, enmarcado en los límites de la subsunción; destellos breves de un "juez Hércules” al calor de las doctrinas del realismo jurídico que se asimilaron de cierta forma en Cuba, y aparición de un modelo de "juez Hermes" que deja traslucir una honda preocupación por la solución de los problemas de la sociedad en que se desempeña y que, por ende, no puede ser reducido en su actuar a los dogmas jurídicos y políticos dominantes.

\section{Un Juez activo, un Juez CReador: el papel del Consejo de Gobierno del Tribunal Supremo Popular en la formación de un nuevo Derecho}

\section{Algunos antecedentes teóricos necesarios}

La actualidad jurídica continental ha introducido corrientes doctrinales y movimientos de diversas escalas e influencias, todos ellos colocan en una posición protagónica a la función judicial.

Llama la atención, por ejemplo, una especie de resurgimiento conceptual del denominado activismo judicial. Este movimiento parece tener sus orígenes, como explica el profesor Maraniello, en la década de los cincuenta. En 1954 la Corte Suprema de los Estados Unidos de América, encabezada por el juez Earl Warren, se declara como "activista", con el caso Brown vs. Borrad of Education, mediante el que se ratifica unánimemente la inconstitucionalidad de la segregación racial en las escuelas norteamericanas ${ }^{25}$. No obstante, se ubican antecedentes del activismo judicial en las Siete Partidas de Alfonso el Sabio.

Teixeira, sin embargo, remonta el origen de este movimiento a 1905, también en Estados Unidos, con la decisión Lochner vs. New York, que abre toda una época de invalidaciones de la Corte Suprema de aquel país frente a la intervención estatal en algunas materias económicas. Atribuye este autor al historiador Arthur Schlesinger Jr. el mérito de incorporar el término activismo judicial no solo al léxico jurídico, sino sobre todo al político y popular, mediante un artículo publicado en la revista Fortune intitulado "The Supreme Court: 1947”. Ofrece además una interesante lista de jueces considerados activistas durante la historia judicial norteamericana ${ }^{26}$.

${ }^{25}$ Cfr., Maraniello, P.A., "El activismo judicial, una herramienta de protección constitucional", en Pensar en Derecho, vol. 1, núm. 1, 2012, pp. 125-126.

26 Teixeira, A.V., “Ativismo judicial: nos limites entre racionalidade jurídica e decisão política”, en Revista Direito GV, vol. 8, núm. 1, São Paulo, enero-jun, 2012. Disponible en: http://dx.doi.org/10.1590/ S1808-24322012000100002. Acceso en: 27 de enero de 2014. 
De lo que hemos llamado como "resurgimiento", tal vez en un sentido más adecuado como reactivación de algunos presupuestos conceptuales de este movimiento, sobresalen los puntos de conexión con el neoconstitucionalismo ${ }^{27}$, en la que el activismo judicial, como afirma Hennig, ha ganado "gran notoriedad y actualidad" 28.

De estos elementos teóricos nos interesa, puntualmente, enmarcar algunas de las características esenciales que distinguen al juez, entendido como "activista" que, sin la intención de encuadrarlo arbitrariamente en uno de los modelos propuestos por Ost, bien se acerca a la idea de "juez Hermes" comentada. Estos atributos pudieran resumirse, siguiendo a Morello ${ }^{29}$, así:

- Respeto a la Constitución como norma suprema y a las fundamentaciones jurídicas de las partes

- Búsqueda primordial de la justa solución al caso

- Creatividad en las sentencias

- Protagonismo del tribunal

Como podrá comprobarse más adelante, enfatizaremos en las dos últimas cualidades, muy a tono con la perspectiva de juez defendida desde este estudio.

No pueden obviarse en este punto otras manifestaciones doctrinales que guardan estrecha relación con el realce otorgado a la actividad judicial, esta vez vinculada a la interpretación constitucional y, por extensión, también a la creación del Derecho. En estas coordenadas podemos situar, por ejemplo, a la teoría del derecho viviente.

Uno de los ejemplos hacia los que se enfoca esta doctrina puede localizarse en tiempos de la fundación de los Estados Unidos de América, donde ya se entronizaba el debate sobre la conveniencia de que la Constitución fuese perdurable, o por el contrario, pudiera ser frecuentemente modificada y actualizada. El profesor Carbonell ${ }^{30}$ nos ofrece algunos pasajes epistolares del intercambio entre Jefferson y Madison en las postrimerías

${ }^{27}$ Un movimiento en auge en el contexto jurídico actual, especialmente latinoamericano. Algunos escritos sobre el alcance del término en: Carbonell, M. (ed.), Neoconstitucionalismo, Editorial Trotta, Madrid, 2003; Valadés, D.; Carbonell, M. (coords.), Constitucionalismo iberoamericano del siglo XXI, UNAM-Cámara de Diputados, México, 2004; Gil Domínguez, A., Neoconstitucionalismo y derechos colectivos, Ediar, Buenos Aires, 2005; Aldunate Lizana, E., "Aproximación conceptual y crítica al neoconstitucionalismo”, en Revista de Derecho, Valdivia, vol. XXIII, núm. 1, jul. 2010, pp. 79-102. En Cuba: Méndez López, J.; Cutié Mustelier, D., "La participación popular en el nuevo constitucionalismo latinoamericano”, en Revista Cubana de Derecho, núm. 36, 2010, pp. 5-24 y Villabella Armengol, C. M., "Constitución y democracia en el nuevo constitucionalismo latinoamericano”, en Ius. Revista del Instituto de Ciencias Jurídicas de Puebla, núm. 25, 2010, pp. 49-76.

${ }^{28}$ Hennig Leal, M. C., "La jurisdicción constitucional entre judicialización y activismo judicial: ¿existe realmente 'un activismo' o 'el activismo'?”, en Estudios Constitucionales, Santiago de Chile, vol. 10, núm. 2, 2012. Disponible en: http://dx.doi.org/10.4067/S0718-52002012000200011. Acceso en: 12 de febrero de 2014.

${ }^{29}$ Cit. pos. Maraniello, P.A., en op. cit., p. 128

${ }^{30}$ Cfr., Carbonell, M., "La constitución viviente", en Isonomía núm. 35, 2011, pp. 187-193; Carbonell, M., "Sobre la Constitución viviente", en Revista Facultad de Derecho y Ciencias Políticas, Universidad Pontificia Bolivariana de Medellín, vol. 42, núm. 117, 2012, pp. 347-357. 
del siglo XVIII sobre este tema. Esto viene a reproducirse hoy en la discusión entre los defensores de una noción de "constitucionalismo viviente", de un Derecho vivo, enriquecido desde la interpretación judicial, frente a los denominados originalistas, más conservadores, que propugnan que tal interpretación solo debe acontecer en los términos de los redactores de estas normas fundamentales.

De una manera muy convincente el ascenso de la influencia de la jurisdicción constitucional y el valor normativo concedido a sus decisiones pone de relieve una inclinación hacia el papel activo del juez, no solo como mero intérprete de la norma. Acontece, como afirma Zagrebelsky, que basado en esta concepción o fórmula del "derecho viviente" -que insistimos brinda al juez un rol protagónico-, "se entiende la norma de ley no en las abstractas posibilidades interpretativas que descienden de los textos, sino la norma de ley tal como 'vive' en la interpretación consolidada de los jueces"31.

Estas concepciones continúan ganando terreno no solo en los espacios académicos, sino en la práctica social, contribuyendo a configurar un ideal de juez profundamente permeado de los elementos sociológicos circundantes. Permite, al mismo tiempo, confirmar que existe una verdadera "jurisprudencia viviente" convertida "en el lugar del derecho que, desde el punto de vista de los destinatarios, cuenta mayormente" 32 . Como ha afirmado Taruffo, "es la jurisprudencia la que constituye el contenido efectivo del derecho viviente, el cual representa en muchos casos el único derecho del cual disponemos" 33 .

\section{Reconocimiento constitucional del Consejo de Gobierno del Tribunal Supremo Popular y el frágil limite entre interpretación y creación judicial del Derecho}

El Consejo de Gobierno del Tribunal Supremo Popular es el órgano al que, constitucionalmente, se le atribuye la facultad de ejercer, a nombre del Tribunal Supremo Popular, "la iniciativa legislativa y la potestad reglamentaria; toma decisiones y dicta normas de obligado cumplimiento por todos los tribunales y, sobre la base de la experiencia de estos, imparte instrucciones de carácter obligatorio para establecer una práctica judicial uniforme en la interpretación y aplicación de la ley" ${ }^{34}$. Este precepto se reproduce casi literalmente en el artículo 15.2 de la Ley $\mathrm{N}^{\circ} 82$ de 11 de julio de 1997, de los Tribunales Populares, al que le siguen en el artículo 19 un conjunto de atribuciones de esta estructura de gobierno de la máxima instancia judicial del país. En el Reglamento aprobado en la misma fecha se prevén otras funciones particulares de este órgano.

Esta relevancia constitucional conferida al Consejo de Gobierno es muestra de la importante misión que desempeña dentro del sistema de tribunales. Sin embargo, somos del criterio que la influencia creciente de sus decisiones sobrepasa los marcos del sistema

31 Zagrebelsky, G., "Realismo y concreción del control de constitucionalidad de las leyes en Italia", en Ferrer, E.; Zaldívar, A. (coords.), La ciencia del Derecho Procesal Constitucional. Estudios en homenaje a Héctor Fix-Zamudio en sus cincuenta años como investigador del derecho, t. VIII, UNAM, México, 2008, p. 424.

32 Ídem, p. 427.

33 Taruffo, M., op. cit., p. 87.

${ }^{34}$ Artículo 121 de la Constitución de la República de Cuba de 24 de febrero de 1976. 
judicial, para aportar valiosas soluciones a problemáticas de orden normativo a las que el legislador no alcanza, bien por las deficiencias advertidas en el proceso legislativo interno ${ }^{35}$, o por las exigencias de la propia dinámica social.

Como se especifica en las tres disposiciones normativas antes mencionadas sobresale entre las facultades del Consejo de Gobierno una de naturaleza interpretativa. O sea, este órgano coadyuva no solo a unificar la interpretación y aplicación de la ley en la actividad judicial, sino que por su propia función interpreta estos preceptos y los traduce en disposiciones de obligatorio cumplimiento para el resto de los tribunales. Recordemos que al tenor del artículo 630.1 de la Ley de Procedimiento Civil, Administrativo, Laboral y Económico, la infracción por falta de aplicación, interpretación errónea o aplicación con trascendencia al fallo de las instrucciones dictadas por el Consejo de Gobierno constituye una causal de casación, esto constituye un mecanismo adicional para garantizar la observancia de dichas disposiciones.

Aquí debemos puntualizar que, según el Reglamento de los Tribunales Populares, se entiende por Instrucción la disposición dictada por el Consejo de Gobierno para dar respuesta a una consulta "cuando la índole propia de las cuestiones de que se trate requieran regular la forma de proceder" (artículo 73). Estas, por regla general, deben ser publicadas en la Gaceta Oficial de la República de Cuba, como establece el artículo 74.

Estos elementos nos sitúan ante la débil frontera entre la interpretación judicial y la creación del Derecho por los tribunales. Mucho se ha escrito sobre las teorías de la interpretación. En el presente espacio solo destacaremos nuestra posición en relación con lo que observamos en el contexto jurídico cubano actual.

En este intento lo primero que advertimos es que se reproducen las tensiones teóricoprácticas en relación con la capacidad creadora del juez, visto en su individualidad, y el producto de su interpretación vinculada a la solución de un caso: la sentencia. Ha primado durante décadas la noción restrictiva asociada a la teoría de la subsunción, típica del legocentrismo continental. Ese "juez jupiterino" ha sido la construcción históricamente idealizada en nuestro escenario jurídico. Pero por debajo de las virtudes que pudieran reconocérsele al modelo mencionado, el concepto de juez que se edificó tenía mucho de mecanicista, de empobrecimiento creativo, de limitaciones raigales definidas por el imperio de la ley.

Por tanto, en esa obediencia irrestricta al mandato legal se produjo la emergencia en las decisiones judiciales de métodos interpretativos demasiado convencionales, que resultaban más o menos en reproducciones literales en las ratio decidendi de las sentencias, de algunos criterios de sala o fundamentos precedentes; inspiraciones doctrinales generalmente uniformes y de escaso valor teórico y olvido de los preceptos constitucionales

${ }^{35}$ Sobre el tema: Carrillo, Y., "Régimen político y calidad de las leyes en Cuba", en Boletín Mexicano de Derecho Comparado, vol. LXIII, núm.128, 2010, pp. 623-669; Carrillo, Y., "Calidad de las leyes en Cuba. Algunos puntos críticos”, en Ratio Juris, vol. 7, núm.14, 2012, pp. 21-51; Méndez López, J., El modelo de creación de leyes en Cuba, tesis en opción al grado científico de Doctor en Ciencias Jurídicas, Universidad de Oriente, Santiago de Cuba, 1999. 
como informadores de la propia decisión ${ }^{36}$. En la doctrina revolucionaria, durante más de cuatro décadas, son muy escasas las referencias relativas a la creación judicial del Derecho, en menor grado todavía a partir de la sentencia individual.

Aun cuando la crítica está hecha, nos permitimos aclarar que en la concepción de jurisprudencia como fuente formal que defendemos no ocupa un lugar principal la sentencia individual. Esto no debe interpretarse en el sentido de devolvernos al punto de origen del problema, sino que entendemos que, por razones sistémicas, las normas de origen judicial en el Derecho cubano deben focalizarse como producto de un juez colectivo, representado justamente por el Consejo de Gobierno del Tribunal Supremo Popular.

Las contradicciones entre interpretación-creación judicial del Derecho no son un problema privativo del ordenamiento jurídico cubano. En los marcos del debate constitucional latinoamericano, por ejemplo, se enfatiza en las dificultades derivadas de la concepción basada en la subsunción, criterio de argumentación al que deberían oponerse, a decir de López Medina ${ }^{37}$, alternativamente, "métodos más audaces de interpretación”, como la ponderación de intereses o derechos en conflicto, las interpretaciones con arreglo a la Constitución y la derrotabilidad de reglas legisladas mediante principios y derechos fundamentales, entre otros. Y el resultado del análisis se nos vuelve igualmente complejo ante la pregunta de si los jueces crean o simplemente aplican el Derecho.

Una respuesta muy cómoda pudiera ser no responder la interrogante basados en la ambigüedad y vaguedad de los términos empleados ${ }^{38}$. Sin embargo, compartiremos en este punto el criterio del profesor Eugenio Bulygin, quien luego de definir las tres posturas más comunes respecto del tema, concluye defendiendo la tesis de que "los jueces no crean derecho en situaciones normales, pero sí lo hacen porque crean normas generales en situaciones muy especiales" 39 . Esta afirmación pudiera desencadenar muchas polémicas, especialmente si se requiriese determinar cuándo estamos ante "situaciones normales” o "especiales” y cuándo no, en fin, términos complejos cuyo análisis excederían el objetivo de este artículo.

Lo cierto es, no obstante, que en esta coordenada se refleja también la contradicción principal entre interpretación y creación jurídicas. Hecho que alcanza al sistema judicial cubano y que proponemos revisar, desde la óptica del mandato constitucional y legal otorgado al Consejo de Gobierno del Tribunal Supremo Popular, en un momento que podemos catalogar de "especial", en donde este órgano del sistema de tribunales adopta normas con un claro carácter de generalidad.

${ }^{36}$ Este hecho demuestra los problemas de directa aplicabilidad de la Constitución cubana en sede judicial. A propósito de esta problemática revísese: Prieto Valdés, M., "En pos de la aplicabilidad directa de la Constitución cubana de 1976 (un breve comentario)", en Ius. Revista del Instituto Jurídico de Puebla, núm. 21, 2008, pp. 193-205.

${ }^{37}$ López Medina, D., El derecho de los jueces en América Latina: historia, usos y técnicas, USAID-San Salvador, 2011, cap. 2.

38 Mantilla, F., "Interpretar: ¿aplicar o crear derecho? análisis desde la perspectiva del derecho privado", en Revista de Derecho de la Pontificia Universidad Católica de Valparaíso, núm. XXXIII, 2 do. sem. 2009, pp. 537-597.

${ }^{39}$ Bulygin, E., “Los jueces ¡crean Derecho?”, en Isonomía, núm.18, 2003, p. 7. 
3. Las instrucciones del Consejo de Gobierno del Tribunal Supremo Popular: nueva forma de creación jurisprudencial del Derecho en Cuba y muestra de las preocupaciones plurales de nuestro "juez Hermes"

Consideramos que la labor del Consejo de Gobierno del Tribunal Supremo Popular en Cuba bien pudiera ejemplificar el rol de ese "juez Hermes” que nos presenta François Ost, sin restar mérito al trabajo de los jueces en su quehacer individual, como también en su práctica colectiva, como institución. Sostenemos esta posición bajo el argumento de que mediante las disposiciones normativas (particularmente las instrucciones) dictadas por este órgano no solo se valida el concepto de "suplencia judicial de la inercia del legislador" ${ }^{40}$, en palabras de Zagrebelsky, o la idea bastante extendida, sobre todo en el sistema anglosajón, de que "la creación del derecho por parte del judicial tiene como fundamento el avanzar los propósitos de la legislación" ${ }^{41}$, sino que se demuestran las crecientes y plurales preocupaciones de nuestro sistema judicial por la solución de las complejas problemáticas jurídicas en el entorno social.

Se han revisado líneas arriba los elementos de definición de las instrucciones dictadas por el Consejo de Gobierno y sus efectos en sede procesal. Aunque de manera muy abierta, se establece como propósito esencial de estas disposiciones normativas regular formas de proceder.

A lo largo del presente artículo se ha hecho referencia a las instrucciones como disposiciones normativas. Esto, en el terreno teórico, también es discutible. Sobre todo para el Derecho Administrativo, donde en algunos casos autores como Gastón Jéze ${ }^{42}$ les desconocen incluso el carácter de fuente de esta rama jurídica.

En el contexto doctrinario cubano se entienden a las instrucciones como instrumentos jurídico-administrativos. Afirma Reyes Paret ${ }^{43}$ que la instrucción "no tiene vida propia e independiente, sino que se debe a una disposición normativa anterior a ella”. Por tanto, son caracteres particulares de este acto la naturaleza exclusivamente administrativa, su limitación formal, la dependencia respecto de otras normas, el carácter de "enseñanza" u "orientación" conferidos, competencia limitada por la norma general anterior a desarrollar y carácter vinculante, etcétera.

En el texto citado, la autora especifica el caso de las instrucciones del Consejo de Gobierno del Tribunal Supremo Popular, extremo que más nos interesa. Enfatiza en el carácter obligatorio que le brinda la propia norma constitucional, y en un efecto más instructivo y explicativo que normativo. A nuestro juicio, de una manera menos clara, se dice que estas instrucciones dependen de otras preceptivas y aunque tienen "rango

${ }^{40}$ Zagrebelsky, G., op. cit., p. 427.

${ }^{41}$ Siguiendo la línea teórica de Hart, cfr., Bix, B., Filosofía del Derecho: ubicación de los problemas en su contexto (trad. de I. Flores; R. Ortiz y J. Vega), UNAM, México, 2010, p. 60.

42 Jéze, G., Principios Generales del Derecho Administrativo (trad. de N. San Millán), t. II, Editorial Depalma, Buenos Aires, [s/f], p. 71.

${ }^{43}$ Cfr., Reyes Paret, Y., "Un primer acercamiento a los instrumentos jurídico-administrativos", en Castanedo, A. et al., op. cit., pp. 563-599. 
constitucional, están revestidas de una menor jerarquía, impidiendo así que modifiquen o deroguen la ley". Nos detenemos en estos aspectos debido, en primer lugar, a que la práctica no coincide con estas conclusiones, así como para mostrar nuestro disentimiento en parte con esta afirmación doctrinal.

Como podrá comprobarse de la revisión de algunas instrucciones del Consejo de Gobierno $^{44}$ el alcance demostrado, las materias reguladas, los cambios esencialmente normativos contenidos, los sujetos a los que vincula y los efectos de su incumplimiento, le confieren a aquellas un especial carácter normativo ${ }^{45}$ que defendemos desde este estudio. Además, no se discute la inferior jerarquía de estas instrucciones, que no por ser mencionadas en el texto constitucional adquieren tal relevancia (desde el principio de jerarquía normativa, claro está). Lo que sucede es que, del examen de las modificaciones en el Derecho positivo introducidas por estas disposiciones, se pueden obtener claras consecuencias del desbordamiento del ámbito material y formal previamente definido desde la óptica administrativista.

Concentrados en el modelo de juez con el que asociamos la actividad de este órgano judicial del Tribunal Supremo Popular podemos afirmar que la variedad de temáticas y las soluciones normativas concretas aportadas por las instrucciones (sin descartar otros aportes realizados mediante dictámenes al evacuar consultas), contribuyen a la integración y sistematización de nuestro ordenamiento jurídico. No solo en el plano de la uniformidad en la interpretación y aplicación de la ley, sino en la creación misma de un nuevo Derecho, dinámico, a tono con las complejas y cambiantes circunstancias en las que se desarrolla la sociedad cubana actual (que confieren rasgo de "situación muy especial” según la tesis de Bulygin).

Este hecho complementa la labor legislativa en el sentido de que da respuesta, en sede judicial, a aspectos no regulados por el legislador y que generan, eventualmente, lagunas normativas de profundas implicaciones para el tracto de las relaciones sociales tuteladas por el Derecho. Aquí se concreta la nueva forma de jurisprudencia que se ha comentado a lo largo del presente escrito.

Estos ejemplos recientes de instrucciones del Consejo de Gobierno y las materias reguladas por ellas pueden servir de colofón a este planteamiento:

- Instrucción $N^{o} 226$, de 26 de noviembre de 2013: pone en vigor la Metodología para la celebración de actos judiciales civiles, de familia, administrativos y económicos, de conformidad con las disposiciones de la Ley de Procedimiento Civil,

${ }^{44}$ El lector puede acceder al compendio de Instrucciones del Consejo de Gobierno del Tribunal Supremo Popular en de la página web www.tsp.cu. En este sitio oficial de la máxima instancia judicial cubana pueden consultarse los Boletines del Tribunal Supremo Popular, en estos se destacan sentencias, acuerdos, dictámenes e instrucciones en cada año judicial, que pueden contribuir mediante su análisis a confirmar las posturas defendidas por los autores.

${ }^{45} \mathrm{La}$ dicotomía entre el reconocimiento o no del valor normativo de las instrucciones desde una mirada administrativa ha sido campo abonado en otros escenarios. Tómese como ejemplo la discusión en la legislación española que se repasa en: Moreno Rebato, M., "Circulares, instrucciones y órdenes de servicio: naturaleza y régimen jurídico”, en Revista de Administración Pública, núm. 147, sept.-dic., 1998, pp. 159-200. 
Administrativo, Laboral y Económico. Aunque puede verificarse una relación de subordinación respecto del mandato de la ley adjetiva, la metodología contiene novedades desde el punto de vista normativo, que se asientan en el componente práctico ("la experiencia judicial”).

- Instrucción $N^{o}$ 221, de 29 de agosto de 2013: establece las reglas para resolver la incompatibilidad en la celebración de actos judiciales penales en que figure un mismo abogado defensor, señalados para la misma fecha, ante tribunales distintos. Es una lógica consecuencia de la dinámica actual de este tipo de procesos, extremo no previsto en su total amplitud en la ley.

- Instrucción $N^{0} 220$, de 16 de enero de 2013: establece requisitos para interponer demandas por incumplimiento de obligación de pago derivadas de contrato, en los procesos ejecutivos y ordinarios de la jurisdicción de las Salas de lo Económico de los tribunales populares. Refleja los cambios que se han venido produciendo en el país en materia de Derecho de Contratos y que han provocado la adopción de medidas legislativas (como el Decreto Ley No 304, de 2013) a los efectos de reordenar las bases jurídicas de la actividad contractual.

- Instrucción $N^{0}$ 218, de 14 de septiembre de 2012: las resoluciones firmes dictadas en los procesos laborales serán ejecutadas por la parte obligada, inmediatamente después de su firmeza; una vez transcurridos los treinta días hábiles siguientes, sin haberse verificado dicho cumplimiento, la parte interesada podrá instar, mediante escrito o verbalmente, al Tribunal que hubiere conocido del asunto en primera o única instancia, a fin de que se inicie el referido trámite de ejecución. Apunta a otro ámbito de la vida social y jurídica del país que pasa por un proceso profundo de transformaciones. Con un sentido garantista, la instrucción precisa los términos para la ejecución, complementando con ello la norma procesal vigente.

- Instrucción $N^{o}$ 216, de 17 de mayo de 2012: esta, a nuestro juicio, es una instrucción paradigmática en cuanto a introducción de elementos normativos se trata. Baste, para su comprensión, reproducir algunos fragmentos del Tercer Por Cuanto, que indica que la precitada disposición se orienta al:

“ (...) modo de proceder respecto a la comparecencia a que se contrae el artículo 42 de la Ley de Procedimiento Civil, Administrativo, Laboral y Económico; el momento en que procede el llamamiento al proceso de terceros con interés legítimo; el modo de proceder para la escucha del menor; la participación del Ministerio Fiscal en estos procesos; las previsiones que deben atenderse para la constitución y el funcionamiento en cada territorio del equipo multidisciplinario; la necesidad de mecanismos que aseguren el ulterior cumplimiento de las obligaciones declaradas por resolución firme, mediante un sistema cautelar propio que incluya la actuación oficiosa de los tribunales y la solicitud a instancia de las partes involucradas, además de la posibilidad de adopción de tutelas urgentes, dada la connotación de los intereses que se protegen; y específicas previsiones para el caso de la ejecución forzosa de lo decidido en firme, para lo cual se debe partir de una visión integradora y armónica del ordenamiento vigente". 
Ciertamente la norma civil sustantiva, el Código de Familia y la ley procesal en la materia no contenían estas especificaciones, que impedían incluso desarrollar los estándares básicos para asegurar la comparecencia de menores en determinadas circunstancias (ausencia de padres, por ejemplo) y limitaba la intervención de otros familiares de gran importancia en el proceso, especialmente los abuelos. Por ende, se desprenden de esta instrucción varias metodologías y reglas que, de manera independiente, forman verdaderos cuerpos normativos que no solo complementan, sino que crean normas nuevas en esta materia. Además, alcanza a un grupo de sujetos muy amplio, que van desde la Fiscalía General de la República, la Organización Nacional de Bufetes Colectivos, hasta las organizaciones sociales y de masas, lo que ratifica lo difícil de asumir que carece de valor normativo por regular solo ámbitos competenciales internos de la administración de justicia.

- Instrucción $N^{o} 215$, de 13 de abril de 2012: sobre procesos ejecutivos y ordinarios sometidos al conocimiento de la jurisdicción económica de los tribunales. Marcó un importante paso en la reordenación de estos asuntos en el país, que habían estado marcados por las moras en la tramitación de los procesos y un número elevado de incumplimientos, sobre todo en el sector estatal, con consecuencias negativas apreciables. Una vez más se manifiesta la honda preocupación desde la función judicial por solucionar los problemas que afectan a la economía interna.

Los ejemplos comentados nos puede permitir movernos en dos direcciones: una, confirmar la orientación heterogénea del sistema judicial hoy en cuanto a la atención a problemáticas que demandan una tutela jurídica más efectiva; otra, la capacidad creadora de este juez colectivo, de atemperar la norma a las condiciones existentes, de introducir elementos de cambio en el ordenamiento interno y se suplir los vacíos normativos no cubiertos por la legislación ordinaria.

Una especie de "juez red", con un alto grado de información (que simula el "banco de datos" que nos comenta Ost), multipolar, frente a un escenario de actores multiplicados, de roles diversificados, frente a paradojas interminables y provisto de nuevos poderes (que preferimos asociar a la capacidad cada vez mayor de resolver cualquier problema, en cualquier dirección) en el complejo entramado que dibuja el Derecho de la contemporaneidad.

Es el juez que participa en el juego jurídico de una combinación creciente de terrenos: económico, familiar, político, etc. Un modelo que también se preocupa por interpretar y reinterpretar la realidad y de encarar otros retos que, a dos décadas de la propuesta de Ost, van evidenciando un profundo impacto social: los problemas de ingeniería genética, de la manipulación biológica de seres humanos, de identidad sexual, de protección de datos, etc. Un juez activo y creador.

Finalmente, buscando al Hermes "mensajero social”, nos quedamos también con el mensaje que, volviendo a los conceptos del Derecho antiguo, debería anunciarnos hoy 
como signo de reflexión: "la restauración de la vieja regla de prudencia de la que cierto Derecho extrae su nombre: prudentia, jurisprudentia, jurisprudencia” 46.

\section{A MOdO DE CONCLUSIONES}

De los aspectos explicados, podemos plantear algunas consideraciones finales. En primer lugar la vigencia y adaptabilidad de los modelos de juez que Ost nos brinda y que reflejan, en buena medida, la evolución de la función judicial, con su proyección de futuro -aun siendo planteados hace dos décadas-. Incluso, no obstante las distancias desde la perspectiva de sistema, consideramos que tales criterios de adaptación son perfectamente aplicables en el contexto jurídico cubano. Nuestro Derecho no ha estado ajeno a las transformaciones que han experimentado la teoría y la práctica jurídicas, especialmente en el sistema continental, hecho que nos acerca más a la dinámica planteada en el estudio de cada modelo de juez descrito por el profesor belga.

De ahí que resulte válido afirmar que, aunque la doctrina nacional no haya acogido extensamente este tópico, el influjo de las teorías que en torno al rol protagónico de la función judicial emergen -o se reactivan - en la actualidad, también pueden explicar tendencias reales en nuestra práctica -particularmente en el desarrollo de la función judicial-. Esta es una de las razones que sostienen nuestra idea de que el Consejo de Gobierno del Tribunal Supremo Popular, como juez colectivo, al tiempo que encarna el modélico "juez Hermes", da vida a una peculiar forma de jurisprudencia, en su sentido de fuente formal (y "norma viva"), como un recurso indiscutible en el proceso de creación e integración del Derecho cubano en la actualidad. Como dato positivo, esta consideración va ganando espacio en la doctrina interna (no sin las tensiones que hemos tratado de advertir en la mencionada confrontación entre posiciones incluyentes y excluyentes en el reconocimiento de las fuentes formales del ordenamiento jurídico) y, fundamentalmente, entre los propios operadores jurídicos (incluidos los jueces).

Este órgano de gobierno del Tribunal Supremo Popular ofrece las más disímiles soluciones a las problemáticas jurídicas que se presentan en pleno proceso de transformaciones sociales y económicas del país (signo de nuestra dinámica social), con lo que se hace evidente el desbordamiento de las facultades interpretativas, para crear efectivamente un nuevo Derecho. De tal forma, mediante sus instrucciones con carácter obligatorio coadyuva a colmar vacíos normativos y a introducir respuestas jurídicas basadas en reglas con alcance general.

Consideramos que este es apenas un acercamiento a un tópico dentro del debate sobre un tema muy complejo, que ha sentido además la influencia del tiempo y las presiones ideológicas y políticas ínsitas en la evolución del Estado y del Derecho en Cuba. Tema que se desdobla en varias aristas, de las que hemos intentado profundizar en algunas esenciales: el reconocimiento de una fuente distinta al acto normativo (la jurisprudencia), y el protagonismo de la función judicial en los procesos de creación del

\footnotetext{
${ }^{46}$ Ost, F., op cit., p. 193.
} 
Derecho (cuando normalmente defender esta postura ha significado oponer esta función a la tradicionalmente dominante en nuestro sistema: la legislativa). Vistos en sus aspectos genéricos, sin embargo, ambas cuestiones convergen, y solo a efectos explicativos hacemos tal distinción.

La visión antes enunciada nos permite asumir que queda mucho terreno, en la teoría y en la práctica, por recorrer. La posible construcción doctrinal y empírica de un "juez Hermes” en el contexto jurídico cubano -que tratamos de introducir en este estudio- no basta para dar respuesta a las profundas contradicciones que siguen en pie alrededor del necesario perfeccionamiento del Derecho y su noción sistémica. Es apenas una provocación intelectual que nos compromete a ahondar más acerca de las perspectivas de la función judicial, su papel activo y creador, así como la materialización del reconocimiento normativo de la jurisprudencia como fuente de nuestro ordenamiento, que junto a otros aspectos que aún continúan siendo asignaturas pendientes para el Derecho cubano, como la definición de un modelo jurisdiccional de control de constitucionalidad de las leyes -que también coloca a los órganos judiciales en una posición relevante-, seguirán sirviendo de asideros para la investigación y la reflexión jurídicas.

\section{BiBLIOGRAFÍA}

Aldunate Lizana, E., “Aproximación conceptual y crítica al neoconstitucionalismo”, en Revista de Derecho, Valdivia, vol. XXIII, núm. 1, jul. 2010, pp. 79-102.

BIx, B., Filosofía del Derecho: ubicación de los problemas en su contexto (trad. de I. Flores; R. Ortiz y J. Vega), UNAM, México, 2010.

Bruzón Viltres, C. J., "El papel activo del juez en el proceso de reconstrucción sistémica del Derecho en Cuba, a partir de la integración de sus fuentes formales", en elDial.com. Suplemento de Derecho Procesal, 25 de marzo de 2014. Disponible en:

HTTP://www.eldial.com/nuevo/lite-tcd-detalle.asp? id = 7327\&base=50\&id_publicar $=\&$ fecha_pu blicar $=25 / 03 / 2014 \&$ indice $=$ doctrina\&suple $=$ Procesal. Acceso en: 26 de marzo de 2014.

, "Fuentes del Derecho en Cuba: indeterminación, efectos, posibles soluciones", en Revista General de Derecho Público Comparado, núm. 14, 2014, pp. 1-31.

, "Jurisprudencia en Cuba: análisis de las consecuencias de su reconocimiento como fuente formal del ordenamiento jurídico”, en Opinión Jurídica, Medellín, vol. 12, núm. 23, 2013, pp. 167-186.

Bruzón Viltres, C. J., Tamayo Blanco, I., "La jurisprudencia en Cuba: reconocimiento dentro del sistema de fuentes del Derecho y posibles consecuencias", en Boletín Mexicano de Derecho Comparado. Nueva serie, vol. XLVII, núm. 139, 2014, pp. 283-315.

Bulygin, E., "Los jueces ¿crean Derecho?”, en Isonomía, núm.18, 2003, pp. 7-23.

Cañizares Abeledo, F. D., Teoría del Derecho, Editorial Pueblo y Educación, La Habana, 1979.

Carbonell, M. (ed.), Neoconstitucionalismo, Editorial Trotta, Madrid, 2003.

Carbonell, M., “La Constitución viviente”, en Isonomía, núm. 35, 2011, pp. 187-193.

, "Sobre la Constitución viviente", en Revista Facultad de Derecho y Ciencias Politicas, Universidad Pontificia Bolivariana de Medellín, vol. 42, núm. 117, 2012, pp. 347-357.

Carrillo García, Y.; Mondelo, W., "Del voluntarismo ontológico al positivismo ideológico (una lectura del pensamiento jurídico cubano)", en Revista Crítica Jurídica, núm. 29, ene.-jun. 2010, pp. 181-217. 
Carrillo, Y., "Calidad de las leyes en Cuba. Algunos puntos críticos", en Ratio Juris, vol. 7 , núm.14, 2012, pp. 21-51.

, "Régimen político y calidad de las leyes en Cuba", en Boletín Mexicano de Derecho Comparado, vol. LXIII, núm.128, 2010, pp. 623-669.

Crisafulli, V., "Jerarquía y competencia en el sistema constitucional de las fuentes”, en Revista de Derecho Constitucional Europeo, núm.1, 2004, pp. 323-353.

David, R.; Jauffret-Spinosi, C., Los grandes sistemas jurídicos contemporáneos (trad. de J. Sánchez Cordero), UNAM-Centro Mexicano de Derecho Uniforme-Facultad Libre de Derecho de Monterrey, México, 2010.

De Bustamante y Montoro, A. S., La jurisprudencia en la jerarquía de las fuentes del Derecho positivo cubano, 2da. ed., Jesús Montero Editor, La Habana, 1937.

Del Cueto, J.A., Discurso leído en la solemne apertura de los tribunales el 2 de septiembre de 1918 , Librería e Imprenta "La Moderna Poesía", La Habana, 1918.

Díez Picazo, L.; Gullón, A., Sistema de Derecho Civil, 8va. ed., Tecnos, Madrid, 1994.

Fernández Bulté, J., Teoría del Estado y el Derecho, 2 tomos, Editorial Félix Varela, La Habana, 2004.

Ferrari Yaunner, M., Los principios de legalidad y seguridad jurídica como fundamentos del proceso de integración del Derecho para colmar las lagunas de la ley en Cuba, tesis presentada en opción del grado científico de Doctor en Ciencias Jurídicas, Universidad de La Habana, 2010.

García Maynez, E., Introducción al estudio del Derecho, 32da. ed., Editorial Porrúa, México, 1980.

GIL Domínguez, A., Neoconstitucionalismo y derechos colectivos, Ediar, Buenos Aires, 2005.

HenNig Leal, M.C., "La jurisdicción constitucional entre judicialización y activismo judicial: ¿existe realmente 'un activismo' o 'el activismo'?”, en Estudios Constitucionales, Santiago de Chile, vol. 10, núm. 2, 2012. Disponible en: http://dx.doi.org/10.4067/S071852002012000200011. Acceso en: 12 de febrero de 2014.

Hierro, L., "El imperio de la ley y la crisis de la ley", en Doxa. Cuadernos de Filosofía del Derecho, núm. 19, 1996, pp. 287-308.

Jawitsch, L.S., Teoría General del Derecho, Editorial de Ciencias Sociales, La Habana, 1988.

JÉze, G., Principios Generales del Derecho Administrativo (trad. de N. San Millán), t. II, Editorial Depalma, Buenos Aires, [s/f].

Lafuente Balle, J.M., La judicialización de la interpretación constitucional, Editorial Colex, Madrid, 2000 .

López Medina, D., "Tres caminos históricos en la formación de la jurisprudencia en América Latina: Recepción y vicisitudes del concepto de 'doctrina legal' en la región”, en González, A. y Del Río, J., (comps.), Discusión jurídica contemporánea desde Michoacán, Tribunal Electoral del Estado de Michoacán, México, 2011, pp. 1-32.

, El derecho de los jueces en América Latina: historia, usos y técnicas, USAID-San Salvador, 2011.

Mantilla, F., "Interpretar: ¿aplicar o crear derecho?, análisis desde la perspectiva del derecho privado", en Revista de Derecho de la Pontificia Universidad Católica de Valparaíso, núm. XXXIII, 2do. sem. 2009, pp. 537-597.

Maraniello, P.A., "El activismo judicial, una herramienta de protección constitucional", en Pensar en Derecho, vol. 1, núm. 1, 2012, pp. 121-165.

Matilla Correa, A., "Comentarios sobre las fuentes del Derecho Administrativo cubano (excepto el reglamento)", en Castanedo, A. et al., Temas de Derecho Administrativo cubano, Editorial Félix Varela, La Habana, 2006, pp. 33-219.

MÉndez López, J., El modelo de creación de leyes en Cuba, tesis en opción al grado científico de Doctor en Ciencias Jurídicas, Universidad de Oriente, Santiago de Cuba, 1999.

MÉNDEz López, J.; Cutié Mustelier, D., "La participación popular en el nuevo constitucionalismo latinoamericano", en Revista Cubana de Derecho, núm. 36, 2010, pp. 5-24. 
Mendoza Díaz, J. et al., Lecciones de Derecho Procesal Civil, Editorial Félix Varela, La Habana, 2001.

Moreno Rebato, M., "Circulares, instrucciones y órdenes de servicio: naturaleza y régimen jurídico", en Revista de Administración Pública, núm. 147, sept.-dic., 1998, pp. 159-200.

Ost, F., "Júpiter, Hércules, Hermes: tres modelos de juez", en Doxa. Cuadernos de Filosofía del Derecho, Universidad de Alicante, núm. 14, 1993, pp. 169-194.

PÉrez Carrillo, J.R., "Causas de indeterminación en el sistema de fuentes del Derecho", en Problema. Anuario de Filosofía y Teoría del Derecho, núm. 4, 2010, pp. 303-322.

Prieto Valdés, M., "En pos de la aplicabilidad directa de la Constitución cubana de 1976 (un breve comentario)", en Ius. Revista del Instituto Jurídico de Puebla, núm. 21, 2008, pp. 193-205.

Raz, J., The Authority of Law, Oxford, Oxford University Press, 1979.

ReYes Paret, Y., "Un primer acercamiento a los instrumentos jurídico-administrativos", en Castanedo, A. et al., Temas de Derecho Administrativo cubano, Editorial Félix Varela, La Habana, 2006, pp. 563-599.

Rodríguez Sánchez, C.F.; Hernández, R., "La jurisprudencia como fuente complementaria del Derecho", en Memorias de la IV Conferencia Científica sobre el Derecho, Santiago de Cuba, Universidad de Oriente, 1997, pp. 39-44.

Simón, L., "Un acercamiento a la jurisprudencia como fuente formal de Derecho: su origen romano y su recepción en Cuba”, en Revista General de Derecho Romano, núm. 10, 2008, pp. 1-12.

Taruffo, M., "Precedente y jurisprudencia”, en Precedente. Anuario Jurídico, 2007, pp. 85-99.

Teixeira, A.V., "Ativismo judicial: nos limites entre racionalidade jurídica e decisão política”, en Revista Direito GV, vol. 8, núm. 1, São Paulo, enero-jun, 2012. Disponible en: http:// dx.doi.org/10.1590/S1808-24322012000100002. Acceso en: 27 de enero de 2014.

VALADÉs, D.; Carbonell, M. (coords.), Constitucionalismo iberoamericano del siglo XXI, UNAMCámara de Diputados, México, 2004.

Villabella Armengol, C.M., "Constitución y democracia en el nuevo constitucionalismo latinoamericano", en Ius. Revista del Instituto de Ciencias Jurídicas de Puebla, núm. 25, 2010, pp. 49-76.

Zagrebelsky, G., "Realismo y concreción del control de constitucionalidad de las leyes en Italia”, en Ferrer, E.; Zaldívar, A. (coords.), La ciencia del Derecho Procesal Constitucional. Estudios en homenaje a Héctor Fix-Zamudio en sus cincuenta años como investigador del derecho, t. VIII, UNAM, México, 2008, pp. 413-427.

Zhidkov, O.; Chirkin, V.; Yudin, Y., Fundamentos de la Teoría Socialista del Estado y el Derecho, Editorial Progreso, Moscú, 1980. 
